\title{
Relevansi Pupuh Durma Pada Mocoan Lontar Yusup dan Kultur Masyarakat Osing Banyuwangi
}

\author{
Handi Wiyono ${ }^{1}$, E.W. Suprihatin ${ }^{2}$, Hartono ${ }^{3}$ \\ Jurusan Seni dan Desain, Fakultas Sastra, Universitas Negeri Malang, Indonesia \\ Email: handi.wiyono.1802526@students.um.ac.id
}

\begin{abstract}
Banyuwangi is a district located on the eastern tip of Java Island which has a unique cultural diversity. This is reflected in the diverse arts. One of the arts in Banyuwangi is macapat which is called Mocoan. The most popular Mocoan performed by the Osing tribal community is the Mocoan Lontar Yusup where the literary work read tells the story of the prophet Yusuf. This art material, which is the focus of research, is studied and analyzed and its relevance is sought for the culture of the people who hold this culture. This study uses a qualitative approach and the data are presented descriptively. Using logical analogies, analyzed based on interactive techniques and based on arguments. Based on the data obtained, it was found that there is a special approach to the expression of the Banyuwangi macapat art, namely in text and song melodies. The special approach is that there are special terminology, meter rules and mining rules. The three data are relevant to the culture of the foreign community, namely exclusive, open, and bound.
\end{abstract}

Keywords: Mocoan Lontar Yusup, osing culture, relevance, pupuh durma

\begin{abstract}
Abstrak: Banyuwangi merupakan kabupaten yang berada di ujung timur Pulau Jawa yang memiliki keragaman budaya yang unik. Hal tersebut tercermin dari keseniannya yang beraneka ragam. Salah satu kesenian di Banyuwangi adalah macapat yang disebut dengan Mocoan. Mocoan yang paling populer dilakukan oleh masyarakat suku osing yaitu Mocoan Lontar Yusup dimana karya sastra yang dibaca berkisah tentang nabi yusup. Material seni ini yang menjadi fokus dalam penelitian, dikaji dan ditelaah serta dicari hubungan relevansinya dengan kultur masyarakat yang memangku kebudayaan ini. Penelitian ini menggunakan pendekatan kualitatif dan data disajikan secara deskriptif. Menggunakan analogi logis, dianalisis berdasarkan teknik interaktif dan berlandaskan argumentatif. Berdasarkan data yang diperoleh, didapatkan bahwa terdapat pendekatan khusus pada ekspresi seni macapat Banyuwangi yakni secara teks maupun melodi tembang. Pendekatan khusus tersebut yakni terdapat terminologi khusus, aturan metrum dan aturan penambangan. Ketiga data tersebut relevan dengan kultur masyarakat osing yakni eksklusif, terbuka, dan terikat.
\end{abstract}

Kata Kunci: Mocoan Lontar Yusup, kultur osing, relevansi, Pupuh Durma

\section{Article info:}

Received: 31 October 2021

Reviewed: 04 November 2021

Accepted: 05 January 2022

\section{PENDAHULUAN}

Banyuwangi adalah kabupaten yang berada di ujung timur Pulau Jawa. tempat ini berbatasan langsung dengan Pulau Bali yang dipisahkan dengan Selat Bali. Banyuwangi juga mempunyai kekayaan alam dan geografis berupa gunung, hutan, dan persawahan. Selain kekayaan alam, keadaan masyarakat juga merupakan suatu kekayaan tersndiri karena Banyuwangi merupakan wilayah yang dihuni masyarakat yang multietnis. Sebagaimana pndapat yang menyatakan bahwa "Penduduk Banyuwangi terdiri dari multi etnis yang mendiami daerahdaerah yang berbeda-beda" (Istiqomah, t.t.).
Berbagai macam suku "terdapat di Kabupaten Banyuwangi seperti Suku Madura, Suku Using, Suku Bali, Suku Mandar, Etnis Tionghoa dan sebagainya”, (Fahad \& Endrayadi, 2017). Keadaan Masyarakat Banyuwangi yang multietnis menyebabkan lahirnya kebudayaan masyarakat yang multikultur. Contoh konkrit ekspresi multikultur tersebut dapat dilihat pada kesenian di Banyuwangi yang beraneka ragam. Misalnya Gandrung, Jaranan Buto, Kuntulan, Barong, Janger, Seblang, dan lain sebagainya. Selain itu, Banyuwangi juga memiliki " tradisi lisan, yang sangat beragam"(Rahmat, 2019). Salah satu keragaman tradisi lisan tersebut 
adalah Mocoan Lontar Yusup. Yaitu "tradisi lisan pelantunan tembang manuskrip kuno berjudul Lontar Yusup yang menjadi salah satu representasi kultural masyarakat Osing" (Indiarti \& Nurullita, 2020). Pada dasarnya tradisi Mocoan ini sama maknanya dengan tradisi macapat, namun dengan nilai kearifan lokal Banyuwangi yang khas. Selain di Banyuwangi, "macapat dengan nama lain juga bisa ditemukan dalam kebudayaan Sunda, Bali, Lombok, dan Madura" (Khoiriyah \& Syarif, 2019).

Lontar Yusup merupakan karya sastra kuno (berwujud buku) yang bertuliskan arab pegon. Kata lontar bukan merujuk bahwa karya sastra ini ditulis di atas daun lontar tapi mempunyai makna kisah perjalanan hidup. Dengan kata lain, Lontar Yusup mempunyai persamaan makna dengan Serat Yusuf karena Lontar Yusup yang tertua di Banyuwangi pun telah ditulis di atas kertas Eropa. Secara struktur, Lontar Yusup terbagi dalam beberapa bagian yang dinamakan pupuh. Pupuh merupakan istilah untuk membagi jenis karya sastra berdasarkan metrumnya yakni Guru Gatra, Guru Lagu, Guru Wilangan. Di dalam Lontar Yusup terdapat "4 Pupuh yaitu Pupuh Kasmaran, Durmo, Pangkur dan Sinom”, (Rofiq dkk., 2016). Pupuh yang dipilih sebagai bahan penelitian adalah Durma dengan alasan bahwa pupuh ini mempunyai keunikan yaitu merupakan satu-satunya pupuh di dalam Lontar Yusuf yang secara struktur berbeda dengan pupuh Durma yang ada di Jawa ${ }^{1}$, namun mempunyai nama yang sama.

Struktur metrum pada pupuh Durma di Lontar Yusuf yaitu 4a, 8a, 7i, 6a, 7a, 8i, 5a, 7i. Kata pupuh di dalam penelitian ini merujuk pada makna tembang (pada pendekatan macapat di jawa) sehingga istilah pupuh pada Lontar Yusup merujuk pada karya sastra yang terikat pada metrum (guru gatra, guru lagu, guru wilangan) tertentu. Pupuh-pupuh dalam Lontar Yusup pada dasarnya sama dengan bentuk tradisi macapat lain yakni karya sastra puisi lama yang dibaca dengan cara ditembangkan/dilagukan dengan melodi tertentu. Demikian pula dengan Lontar Yusup yang "dibacakan atau ditembangkan (puisi yang didendangkan) di hadapan khalayak dalam ritual tradisi selamatan daur hidup

\footnotetext{
${ }^{1}$ Jawa dalam hal ini adalah merujuk pada Jogja dan Solo
}

manusia (kelahiran, sunatan dan perkawinan) maupun ritual tahunan bersih desa, terutama di desa-desa yang dihuni oleh masyarakat Using (Osing)"(Indiarti \& Hasibin, 2019). Kendatipun masih berada di Pulau Jawa, namun pembacaan Lontar Yusup mempunyai ciri khas tersendiri yakni "mendendangkan larik-larik puisi Yusup dalam ragam tembang cara Osing yang berbeda dengan nada tembang orang Jawa pada umumnya"(Indiarti \& Hasibin, 2019). Mocoan dalam lingkup Lontar Yusup mempunyai konotasi pada pembacaan lontar yang bersifat ritual. Sedangkan dalam konotasi profan digunakan istilah pacul gowang.

Kekhasan dalam pembacaan Lontar Yusup dapat dilihat dari melodi yang digunakan dan ragam variasinya. Variasi melodi ini dalam Lontar Yusup disebut dengan tembang. Dalam tradisi membaca pupuh durma terdapat tiga karakteristik melodi yang digunakan. Yakni melodi sakral (yaitu tembang arum-arum dan sumadya), kedaerahan (yaitu tembang dari tiga desa yakni kemiren, cungking, dan mondoluko), dan bait khusus (yaitu pada bait cahyanira). Karakteristik melodi yang kedua yakni yang bersifat kedaerahan inilah yang menjadi fokus di dalam penelitian ini untuk ditemukan relevansinya dengan kultur masyarakat pendukungnya. Hal ini berlandaskan pada asumsi dasar kebudayaan terdiri dari tataran ide, perilaku, dan produk/artefak. Asumsi ini didasarkan pada teori (koentjaraningrat, 2009) mengenai tiga wujud kebudayaan. Dengan demikian, produk kebudayaan yang diteliti (pupuh durma) dicari hubungan relasional dengan kultur masyarakat pendukungnya pada tataran ide dan perilaku. Jika dilihat dari tembang, maka hal pertama yang menjadi keunikan adalah laras yang digunakan pada khazanah karawitan Banyuwangi yaitu slendro Banyuwangi sebagaimana pernyataan "Karawitan Banyuwangi memiliki ciri khas nada sendiri yang hanya menggunakan laras slendro" (Mahendra \& Suwahyono, t.t.).

Keunikan kedua terdapat pada lagu dari masing-masing variasi tembang kedaerahan (kemiren, cungking, dan mondoluko) yang dituangkan dalam notasi angka. Selain itu, sesuai dengan judul maka kata pupuh durma merujuk pada sebuah karya sastra yang berkaitan dengan 
metrum dan tembang yang digunakan untuk membaca/melagukan tembang. Maka, tulisan dalam penelitian ini memfokuskan pada keunikan yang terkandung di dalam pupuh durma yakni dari segi aturan metrum dan aturan penembangannya serta hubungan relvansinya dengan karakteristik masyarakat pendukungnya. METODE

Penelitian ini menggunakan pendekatan kualitatif sehingga peneliti terjun langsung ke lapangan untuk melakukan pengumpulan data melalui wawancara, observasi, dan studi dokumentasi. Jenis pendekatan ini dipilih untuk mendapatkan kedalaman informasi yang sedang diteliti sebagaimana pendapat yang menyatakan bahwa "Fakta, realita, rnasalah, gejala serta peristiwa hanya dapat dipaharni bila peneliti rnenelusurinya secara mendalarn dan tidak hanya terbatas pada pandangan di permukaan saja. Kedalaman ini yang rnencirikhaskan metode kualitatif, sekaligus sebagai faktor unggulannya"(Raco, 2018). Ketiga teknik pengumpulan data di atas diperuntukkan agar meningkatkan derajad keabsahan data dalam proses triangulasi metode pengumpulan data. Peneliti ditempakan sbagai instrumen utama penelitian sebagaimana "Salah satu ciri penelitian kualitatif adalah peneliti bertindak sebagai instrumen sekaligus pengumpul data. Instrumen selain manusia (seperti: angket, pedoman wawancara, pedoman observasi dan sebagainya) dapat pula digunakan, tetapi fungsinya terbatas sebagai pendukung tugas peneliti sebagai instrumen kunci" (Wahidmurni, 2017). Wawancara dilakukan kepada pembaca Lontar Yusup dari ketiga desa (Kemiren, Cungking, dan Mondoluko) dan praktisi Mocoan Lontar Yusup di kecamatan glagah. Observasi dilakukan pada Lontar Yusup transliterasi untuk mendapatkan data mengenai aturan metrum yang terdapat pada pupuh durma, selain itu dilakukan pula observasi dan dokumentasi pada pembacaan Lontar Yusup dan tembangnya sebagai data aturan penembangan.

Analisis data pada penelitian ini menggunakan Model Analisis Interaktif yang dikemukakan oleh Milles dan Huberman. Pada analisis data model interaktif ini terdapat tiga komponen utama yakni reduksi data, sajian data, dan penarikan kesimpulan. "ketiga komponen utama yang terdapat dalam analisis data kualitatif itu harus ada dalam analisis data kualitatif, sebab hubungan dan keterkaitan antara ketiga komponen itu perlu terus dikomparasikan untuk menentukan arahan isi simpulan sebagai hasil akhir penelitian" Miles dan Huberman (1984:23) dalam (Nugrahani \& Hum, 2014). Proses analisis data pada model interaktif ini dimulai sejak awal pengumpulan data di lapangan. Data dikumpulkan sembari peneliti melakukan proses analisis data hingga dapat menarik kesimpulan akhir. Pada akhirnya data akan disajikan dalam bentuk pernyataan ilmiah dan analogi logis argumentatif serta diuraikan secara deskriptif.

\section{HASIL DAN PEMBAHASAN Aturan Metrum}

Pada dasarnya struktur metrum pada pupuh Durma di Lontar Yusuf yaitu 4a, 8a, 7i, 6a, 7a, 8i, 5a, 7i. Namun pada beberapa pada (bait) terdapat guru lagu yang berbeda khususnya baris pertama. berikut adalah contohnya. Pada Pupuh VII Durma bait ketiga dan keempat baris pertama menggunakan guru lagu 4e. Pada bait ke enam dan ke sepupuh baris pertama menggunakan guru lagu 4i. Pada bait ke 9 baris pertama menggunakan guru lagu $4 u$. Selain itu guru lagu, terdapat keragaman lain yaitu pada guru wilangan. Pada bait ke 37 baris pertama menggunakan guru wilangan $3 \mathrm{a}$. Contoh kedua adalah pada bait ke 48 baris pertama dan kedua menggunakan guru wilangan 9a, 5a. Pada bait ke 49 baris pertama menggunakan guru wilangan $5 \mathrm{u}$. Dari beberapa contoh di atas dapat dilihat bahwa secara teks pupuh durma tidak terikat dengan aturan secara kaku.

\section{Aturan Penembangan}

Telah diketahui bahwa tradisi pelantunan pupuh durma mempunyai versi yang berbeda di setiap daerah. Pada awalnya, hanya terdapat satu tembang (versi melodi) dalam membaca Lontar Yusup khususnya Pupuh Durma. Namun seiring berjalannya waktu, banyak versi bermunculan. Hal ini dikarenakan tradisi Mocoan Lontar Yusup dilakukan selama semalam suntuk. Jadi, jika menggunakan pola melodi yang sama, akan mengalami kebosanan. Munculnya berbagai variasi tembang ini dari beberapa orang dari desa berbeda yang berguru pada seorang juru tembang Lontar Yusup. Ketika sudah menguasai tembang dari seorang guru, mereka pulang ke desa masing-masing dan mengembangkan melodi (tembang) tersebut sesuai kreativitasnya sehingga menjadi identitas versi salah satu desa. Bahkan, hingga penelitian ini ditulis, pengembangan melodi dan penciptaan melodi baru dalam pembacaan Lontar Yusup masih 
Handi Wiyono ${ }^{1}$, E.W. Suprihatin ${ }^{2}$ Hartono $^{3}$

Relevansi Pupuh Durma Pada Mocoan Lontar Yusup dan Kultur Masyarakat Osing Banyuwangi

diperbolehkan. Variasi tembang yang bersifat kedaerahan dalam pembacaan pupuh Durma terdapat tiga versi yakni Kemirenan, Mondoluko, dan Cungking. Ketiga versi ini dapat ditulis dalam notasi angka sebagai berikut:

1. Versi Tembang Kemiren

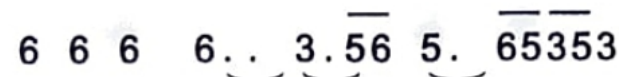

A na cri ta

$\begin{array}{llllllll}3 & 3 & 3 & 3 & 3 & 3 & 3 & 3\end{array}$

Sa tu man jing ing su war ga

$\begin{array}{lllllll}3 & 3 & 3 & 3 & 3 & 5 & 2\end{array}$

La li ma gung a neng gih

$\begin{array}{lllllll}2 & 2 & 1 & 3 & 653 & 3 & 3\end{array}$

Sawiji (a) su alas

$\begin{array}{llllllll}6 & 1 & 3 & 2 & 1 & 3 & 1 & 2\end{array}$

Kang a bi sa re ra san

$\begin{array}{lllllllll}2 & 2 & 2 & 2 & 2 & 2 & 2 & 1 & 1\end{array}$

Ma tu ring na bi ya kub $u$ ni

$\begin{array}{lllllllll}3 & 5 & 2 & 1 & 2 & 1 & 2 & 6 & 6\end{array}$

Ka pin do on ta

$\begin{array}{llllllll}1 & 2 & 2 & 2 & 3 & 53212 & 2 & 2\end{array}$

Ni ra ba gen da saleh
2. Versi Tembang Cungking

$\begin{array}{lllll}6 & 6 & 6 & 5 & 3\end{array}$

A na cri ta

$\begin{array}{llllllll}3 & 3 & 3 & 3 & 565 & 2 & 1 & 6\end{array}$

Sa tu man jing ing se war ga

$\begin{array}{llllllll}1 & 2 & 2 & 2 & 2 & 2 & 2 & 2\end{array}$

La li ma gung a neng gih

$\begin{array}{lllllll}6 & 6 & 6 & 3 & 653 & 3 & 3\end{array}$

Sawiji (a) su a las

$\begin{array}{llllllll}6 & 1 & 3 & 2 & 1 & 3 & 1 & 2\end{array}$

Kang a bi sa re ra san

$\begin{array}{lllllllll}2 & 2 & 2 & 2 & 2 & 2 & 2 & 2 & 2\end{array}$

Ma tu ring na bi ya kub $u \quad n i$

$6 \underbrace{2} 2 \quad 1 \ldots 321696$

Ka pin do onta

$\begin{array}{llllllllllll}1 & 2 & 2 & 2 & 3 & 5 & 3 & 2 & 1 & 2 & 3 & 2\end{array}$

Ni ra ba gen da saleh 
3. Versi Tembang Mondoluko

$\begin{array}{lllll}3 & 5 & 5 & 5 \ldots 651653253\end{array}$

\section{A na cri ta}

\section{$\begin{array}{lllllllll}2 & 1 & 1 & 1 & 2 & 3 & 5 & 1 & 6\end{array}$}

Sa tu manjing ing se war ga

\section{$\begin{array}{lllllll}1 & 2 & 2 & 2 & 2 & 2 & 2\end{array}$}

\section{La li ma gung a neng gih}

\section{$\begin{array}{lllllll}1 & 1 & 1 & 3 & 653 & 3 & 3\end{array}$}

Sawi ji(a) su a las

$\begin{array}{llllllll}6 & 1 & 3 & 2 & 1 & 3 & 1 & 2\end{array}$

Kang a bi sa re ra san

$\begin{array}{lllllllll}2 & 2 & 2 & 2 & 2 & 2 & 2 & 1 & 1\end{array}$

Ma tu ring na bi ya kub $u$ ni

\section{$\begin{array}{lllllll}3 & 1 & 2 & 1 & 2 & 6 & 6\end{array}$ \\ Ka pin do on ta

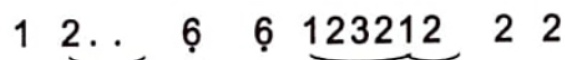 \\ Ni ra bagenda sa leh}

Ketiga tembang di atas menggunakan laras slendro Banyuwangi dengan nilai interval yang sepadan dengan interval berikut ini:

Tabel 1. Keterangan Notasi

\begin{tabular}{c|c} 
Notasi & Nilai \\
\hline 1 & $\mathrm{E}$ \\
\hline 2 & $\mathrm{~F}^{\#}$ \\
\hline
\end{tabular}

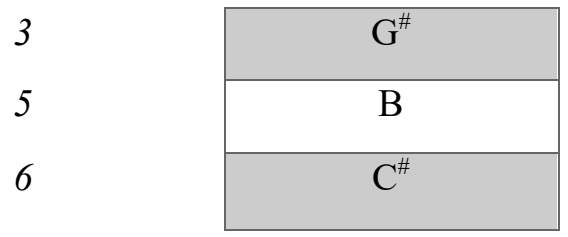

Selain itu, terdapat pula aturan penembangan dalam Lontar Yusup yang diberi nama ngrancak atau mecel, yaitu cara membaca Lontar Yusup dengan tempo yang lebih cepat. Hal ini dilatarbelakangi oleh ritual Mocoan Lontar Yusup yang dilakukan selama semalam suntuk. Jika pada waktu hampir pagi dan bagian pada Lontar Yusup belum selesai dibaca (menurut estimasi waktu juru tembang), maka cara membaca Lontar Yusup dipercepat temponya.

Di samping aturan di atas, ada satu istilah lagi yang dinamakan dengan pasrahan, yakni dalam teknik membacanya, Lontar Yusup dibacakan oleh beberapa orang dalam satu kelompok secara bergantian. Sebelum lontar dibaca oleh juru tembang pada giliran selanjutnya, maka juru tembang sebelumnya akan membaca bait terakhir dengan memperlambat tempo dan memberikan beberapa ornamentasi. Hal ini bertujuan agar juru tembang selanjutnya tidak tepengaruh oleh nada dasar yang dipakai oleh juru tembang sebelumnya, sehingga sebagai antisipasi kemampuan potensi vokal dan range nada yang dimiliki setiap orang.

Hasil penelitian di atas dirumuskan bahwa Pupuh Durma ditinjau dari segi teks dan tradisi lisan (pembacaannya) mempunyai tiga karakteristik yang relevan dengan karakter masyarakat osing Banyuwangi yakni eksklusif, terbuka, dan terikat. Klasifikasi karakteristik ini didasarkan pada analisis yang dilakukan pada pupuh durma, merumuskan klasifikasi berdasarkan analogi logis yang argumentatif dan secara ulang alik dicari hubungan relasional dengan karakteristik kultur masyarakatnya pada tataran ide dan perilaku berdasarkan data penelitian sebelumnya. Ketiga karakteristik tersebut dapat dijabarkan sebagai berikut:

\section{Eksklusif}

Sifat yang pertama ini dapat dilihat dari pendekatan macapat di Banyuwangi yang mempunyai sifat yang khas. Kehkhasan tersebut dapat terlihat dari penggunaan istilah. Kekhasan penggunaan istilah akan membentuk paradigma berpikir berdasarkan terminologi yang digunakan. Sebagaimana pernyataan yang menyatakan bahwa " berbahasa tidak lepas dari kegiatan berpikir dengan kerangka 
budayatertentu,"(Wahyudiono, 2019). Untuk memahami seni macapat Banyuwangi juga diperlukan pemahaman terhadap terminologi yang digunakan karena istilah yang sama akan mempunyai makna yang berbeda jika berada pada kebudayaan masyarakat yang berbeda. Dengan demikian dapat dikatakan bahwa kultur masyarakat osing mempunyai karakteristik yang eksklusif yakni mempunyai kekhasan sendiri yang membedakan dengan kultur masyarakat di luar osing. Hal ini sebagaimana pendapat yang menyatakan bahwa "Banyuwangi yang terletak di pulau Jawa memiliki kebudayaan yang lebih spesifik dari kota lain di pulau Jawa" (Lesmana $\&$ Sudikan, t.t.).

Kekhasan tersebut telah diteliti oleh Lekkerkerker (1923:1031), yang berpendapat bahwa kepribadian, bahasa, dan adat orang Using sangat berbeda dari orang Jawa lainnya. Selain itu, pada Kongres Bahasa Jawa pertama di Semarang pada Juli 1991 telah disepakati bahwa bahasa osing merupakan bahasa sendiri dan bukan merupakan sub bagian dari Bahasa Jawa (Wahyudiono, 2019) sehingga semakin terlihat jelas bahwa kultur masyarakat osing bersifat eksklusif yang relevan dengan ekspresi budaya di dalam tradisi Mocoan Lontar Yusup.

\section{Terbuka}

Karakteristik kedua ini dapat dilihat dari bermacam-macamnya variasi tembang yang digunakan dalam satu pupuh. Dalam membaca satu pupuh tidak terikat pada satu lagu/melodi tertentu saja, namun dapat berkembang sesuai kreativitas masyarakatnya. Hal ini menunjukkan sifat keterbukaan masyarakat yang tinggi terhadap pluralisme dan dinamis terhadap aturan. Bukti sifat terbuka dapat dilihat pula pada teks dalam pupuh durma Lontar Yusup yang tidak terpaku pada aturan metrum yang kaku. Lontar Yusup yang tergolong berusia tua (ditulis di Desa Cungking) berangka tahun 1829 sehingga sifat dinamis terhadap aturan ini sudah lama terbentuk dan mengakar di dalam karakter masyarakat osing. Sifat masyarakat osing yang terbuka ini dilandasi oleh karakter mereka yang "menghargai perbedaan dengan tenggang rasa" (Hanafi dkk., 2018) sehingga perbedaan tidak menjadi pemicu perpecahan dan malah memperkaya ekspresi budaya mereka.

Keterbukaan masyarakat osing telah membudaya terlihat dalam Buku Inventarisasi Kemiren yang ditulis tahun 2017 menyatakan bahwa Suku Osing terbuka dengan hal-hal baru dan mementingkan kepentingan bersama (Wijaya \& Purwanto, 2017). Wujud keterbukaan masyarakat osing terlihat pula pada ekspresi seni masyarakatnya yang melakukan akulturasi dengan budaya di luar osing. Seperti misalnya pada kesenian iringan seni gandrung yang "mempergunakan instrumen musik barat, biola (setelah Belanda masuk ke daerah Blambangan)", (Azizah, 2014). Bukti kedua terlihat pada omprog (mahkota) gandrung yang menggunakan "ornamen Antareja menggambarkan manusia berbadan ular" (Wahyudiono, 2019).

Hal ini menunjukkan walaupun kultur masyarakat osing eksklusif seperti diungkap pada poin 1, tetapi tidak menutup kemungkinan untuk melakukan akulturasi kebudayaan karena sifat masyarakatnya yang terbuka. Selain dari bukti ekspresi seni di atas, keterbukaan masyarakat osing terlihat pada kultur pada taraf perilaku masyarakatnya yakni bahasa. " Hierarki ataupun stratifikasi bahasa pada masyarakat Osing tidak ada" (Wahyudiono, 2019). Pada bahasa using tidak dikenal stratifikasi bahasa spserti pada masyarakat Jawa (ngoko, krama madya, krama alus). Bahasa osing bersifat terbuka dan sama penggunaannya terhadap siapa pun. Hal ini merupakan representasi karakteristik masyarakatnya yang bersifat terbuka dan egaliter sebagaimana pernyataan " bahasa tutur masyarakat Osing itu menunjukkan hubungan keakraban yang bersifat egaliter". (Serikit, 2009).

\section{Terikat}

Karakteristik Pupuh Durma yang ketiga adalah terikat. Keterikatan dapat dilihat pada dua sisi yaitu teks dan variasi tembang. Dari sisi teks keterikatan yang dapat dilihat adalah bahwa perubahan metrum tidak terjadi secara ekstrim. Pada bagian tertentu hanya berbeda pada guru lagu dan guru wilangan. Dari sisi variasi tembang (melodi) tetap terikat pada satu laras dengan interval yang sama yakni slendro Banyuwangi. Dengan demikian, karakteristik keterbukaan pada poin 2 di atas tidak serta merta merubah esensi secara radikal, tetapi lebih bersifat mengembangkan dan masih mempertahankan "sesuatu" yang sifatnya fundamental. Ekspresi budaya tersebut berkorelasi dengan karakteristik masyarakat Banyuwangi yaitu yang pertama adalah weluri. "Weluri merupakan metode yang dilakukan masyarakat Osing dalam mempertahankan nilai- 
nilai budayanya dari generasi ke generasi" (Hanafi dkk., 2018). Hal ini mengindikasikan bahwa kultur masyarakat osing terbuka terhadap perubahan dan pembaharuan, tetapi di sisi lain masih mempertahankan beberapa aspek dari khasanah budayanya untuk mempertahankan identitas. Hal ini diperkuat oleh pendapat yang menyatakan bahwa "masyarakat Osing dikenal kuat dalam mempertahankan nilai-nilai budaya dan karakter kesukuan mereka", (Istiqomah, T.T.). Nilai kultural kedua masyarakat osing yang mendukung keterikatan ini adalah sawitan. "Sawitan memiliki makna seragam bagi masyarakat Osing.

Masyarakat Osing menjunjung tinggi keseragaman antar anggota suku Osing" (Hanafi dkk., 2018). Dari nilai kultural sawitan ini dapat dilihat bahwa masyarakat mempunyai karakteristik terikat antara satu dengan yang lain untuk membentuk satu identitas, yakni osing. Hal ini relevan dengan temuan penelitian bahwa ekspresi budaya yang terdapat pada Lontar Yusup dan tradisi pembacaannya masih terikat pada elemen tertentu. Selain pembahasan di atas, masih terdapat banyak peluang dan kemungkinan yang belum digali dari Lontar Yusup ini. Baik dari segi tekstual, aturan, maupun tradisi yang menghidupinya. Masih terdapat versi melodi yang bersifat khusus dan sakral dan hubungannya dengan dunia simbol. Kiranya hasil penelitian ini dapat menjadi pemantik untuk penelitian berikutnya

\section{KESIMPULAN}

Dari pembahasan di atas dapat ditarik kesimpulan bahwa pupuh Durma pada tradisi Mocoan Lontar Yusup di Banyuwangi mempunyai korelasi dengan karakteristik kultur masyarakat pemangku budayanya. Hal tersebut dapat dilihat dari karakteristik teks (aturan metrum) dan variasi tembang dalam tradisi membaca sebagai ekspresi budaya benda dan tak benda mempunyai kesamaan karakteristik dengan kultur masyarakat osing pada taraf ide dan perilaku yakni dapat dirumuskan dalam tiga karakter yaitu eksklusif, terbuka, dan terikat. Ketiga karakteristik ini saling melengkapi dan berjalan secara dinamis.

\section{DAFTAR PUSTAKA}

Azizah, F. N. (2014). Gandrung Dalam Upacara Ritual Petik Laut Di Pantai Muncar Kabupaten Banyuwangi. Makalangan, 1(1).

Fahad, H. A., \& Endrayadi, E. C. (2017). Pengembangan Sektor Pariwisata Di
Kabupaten Banyuwangi Tahun 2002-2013. Publika Budaya, 5(1), 28-35.

Hanafi, H., Hidayah, N., \& AT, A. M. (2018). Adopsi Nilai Budaya Osing Dalam Kerangka Objektivitas Meaning Of Life. Jurnal Pendidikan: Teori, Penelitian, Dan Pengembangan, 3(9), 1237-1243.

Indiarti, W., \& Hasibin, N. (2019). Lontar Yusup Banyuwangi: Warna Lokal Dan Variasi Teks Dalam Manuskrip Pegon Di Ujung Timur Jawa. Manuskripta, 9(1), 1-23.

Indiarti, W., \& Nurullita, H. (2020). Geliat Kaum Muda Dalam Preservasi Tradisi Mocoan Lontar Yusup Di Banyuwangi. UNEJ E-Proceeding, 506-518.

Istiqomah, A. W. N. (T.T.). Etnopedagogi Tradisi Lisan Basanan Suku Osing DI Kecamatan Glagah Kabupaten Banyuwangi Dan Pemanfaatannya Sebagai Buku Ilmiah Populer.

Khoiriyah, F., \& Syarif, Z. (2019). Eksistensi Tembang Mamaca (Macapat) Dalam Dimensi Kultur, Mistik Dan Religius. Tribakti: Jurnal Pemikiran Keislaman, 30(2), 324-334.

Koentjaraningrat. (2009). Pengantar Ilmu Antropologi: Vol. IX (Revisi 2009). PT Rineka Cipta.

Lesmana, I. B., \& Sudikan, S. Y. (T.T.). Pola Budaya Banyuwangi Dalam Novel Karya Hasnan Singodimayan Sebagai Pengenalan Budaya Pada Materi Tematik Pendidikan Dasar. Eduhumaniora| Jurnal Pendidikan Dasar Kampus Cibiru, 11(1), 46-54.

Mahendra, S., \& Suwahyono, A. (T.T.). Pembelajaran Ekstrakurikuler Karawitan Banyuwangi Di Smpn 2 Rogojampi.

Maulana, A. R. (2021). Eksistensi Aksara Arab Pegon Dalam Naskah Mocoan Lontar Yusuf Budaya Suku Osing Banyuwangi. Semnasbama, 5, 239-251.

Nugrahani, F., \& Hum, M. (2014). Metode Penelitian Kualitatif. Solo: Cakra Books.

Raco, J. (2018). Metode Penelitian Kualitatif: Jenis, Karakteristik Dan Keunggulannya.

Rahmat, L. I. (2019). Kajian Antropologi Sastra Dalam Cerita Rakyat Kabupaten Banyuwangi Pada Masyarakat Using. KREDO: Jurnal Ilmiah Bahasa Dan Sastra, 3(1), 83-93.

Rofiq, A. A., Degeng, I. N. S., Hidayah, N., \& Atmoko, A. (2016). Nilai-Nilai Budaya Suku Using Banyuwangi Dalam Kitab Lontar Yusuf Dan Aplikasinya Pada 
Handi Wiyono ${ }^{1}$, E.W. Suprihatin ${ }^{2}$, Hartono $^{3}$

Relevansi Pupuh Durma Pada Mocoan Lontar Yusup dan Kultur Masyarakat Osing Banyuwangi

Konseling. Disertasi Tidak Diterbitkan, Malang: Pascasarjana Universitas Negeri Malang.

Serikit, P. S. R. M. (2009). Pola Komunikasi Masyarakat OSING (Studi Tentang Pola Komunikasi Masyarakat Suku Osing Desa Kemiren Kecamatan Glagah Kabupaten Banyuwangi Jawa Timur).
Wahidmurni, W. (2017). Pemaparan Metode Penelitian Kualitatif.

Wahyudiono, A. (2019). Kajian Bahasa Osing Dalam Moderenitas. Fkip E-Proceeding, 71-86.

Wijaya, P. Y., \& Purwanto, S. A. (2017). D164Studi Rumah Adat Suku Osing Banyuwangi Jawa Timur. Simposium Nasional RAPI XVI, 16(1), 117-123. 